\title{
The low- level laser therapy in temporo-mandibular disorders-an update of the current literature
}

\author{
Smaranda Buduru1, Oana Baru², Anca Mesaroș ${ }^{3}$
}

Corresponding author: Baru Oana, E-mail address: oanabaru@gmail.com

1 Prosthodontics Departement, "Iuliu Haţieganu” University of Medicine and Pharmacy Cluj-Napoca, Cluj-Napoca, Romania

\begin{abstract}
Temporo-mandibular disorders (TMD) have become a frequently encountered pathology. Its complexity requires a higher degree of knowledge in matters of diagnosis and treatment. Although the diagnosis aspect has a golden standard represented by magnetic resonance imaging (MRI), the treatment part is not completely understood. Low-level laser therapy (LLLT) has been used as one of the tools to treat TMD for more than ten years now. The aim of this study is to evaluate the scientifically based evidence on the efficacy of low-level laser therapy in the treatment of TMD.

Material and methods: An electronically search of the PubMed and Science Direct data bases has been performed starting from 2008 and up to June 2018. Selection criteria included: human subjects, articles written in English, review type articles.

Results: After a careful review of the aforementioned databases, we have included in this present update a number of 10 articles. Conclusion: The association between TMD and LLLT seems to bring about an improvement of the symptoms related to this pathology. Although the results in reducing pain and improving oral function are encouraging, the heterogeneous laser parameters used in therapy and lack of standardization does not allow the elaboration of a certain clinical guideline. Further research is recommended to establish an evidenced-based protocol.
\end{abstract}

Key words: low-level laser therapy, temporomandibular disorders, review

\section{Introduction}

Temporo-mandibular joint (TMJ) pathology is considered to be very complex. The clinical signs and symptoms of the cervical structures, TMJ, masticatory muscles and even the surrounding structures (teeth, periodontium) have been reunited under the name of temporomandibular disorder [1]. More than one classification of the TMD can be found in the current literature in the field. Jeffrey Okeson has established a comprehensive taxonomy [1], but the most commonly used have been elaborated by the American Academy of Orofacial Pain (AAOP) [2] and the Research Diagnostic Criteria for Temporomandibular Disorders (RDC/TMD) [3]. They include disc displacements, inflammatory, noninflammatory, and congenital diseases, and fractures or anchyloses.

The etiopathogenesis of the temporomandibular disorders is controversial. Many theories have been proposed over the years to determine their causes such as: the traumatic, biomechanical, occlusal, joint hyper mobility, microbiological or hormonal theory $[4,5,6,7,8]$. As a result, a multidisciplinary approach in the treatment of the TMD has been developed: manual therapy, occlusal splint therapy, electrotherapy, ultrasound, transcutaneous electrical nerve stimulation (TENS) or laser therapy [9,22].
Low-level laser therapy (LLLT) has drawn the attention due to its easy application, short treatment visit and few contraindications. Its effectiveness is still under evaluation and the results are controversial. In the present study, we have applied meta-analysis in reviewing the scientific articles published in journals during the last 10 years with the view to provide some clinical practice guidelines.

\section{Methods}

\section{Search strategy and selection criteria}

We performed an electronical search of the Pubmed and Science Direct data bases starting from January 2008 and up to June 2018. Before initiating our search, careful attention was paid to the Preferred Reporting Items for Systematic Reviews and MetaAnalyses (PRISMA) statement guidelines [10,11,12]. We included the following search terms: "temporomandibular disorder(s)" OR “TMD” OR "temporomandibular joint disorder" OR “TMJ disorder” OR “TM disorder” AND "low-level laser therapy” OR “LLLT” OR “laser therapy” OR “diode laser".

The inclusion criteria were as follows: randomized clinical trials involving patients with TMD, articles written in English, meta-analysis studies in which LLLT was the treatment option for TMD. The exclusion criteria were: studies performed on patients 
with systemic diseases or pain not related to TMJ, abstracts that did not report data on the results of interests.

2. Study selection and data extraction

All the authors involved in the present study performed a screening of the possible relevant titles and abstracts. Next, full-text articles were obtained from the journals taken into consideration. Data extracted from the included studies contained: general information about the publication (year, author), number of patients taken into consideration, treatment-related information (type of laser used and its characteristics, duration, number of meetings) and clinical outcomes.

\section{Results}

Focus questions

1. What are the indications of LLLT in TMJ pathology?

Low level laser therapy has been used for more than 20 years in various cases of acute or chronic muscles or skeletal pathologies due to its biostimulative, regenerative, analgesic or anti-inflammatory effect [13]. When it comes to the use of LLLT in TMJ pathology, the literature is controversial, meaning that some authors have obtained no differences between the control the placebo group, whereas others have declared relevant statistic differences in favor of the LLLT [21,23,24].

The clinical indications for use of LLLT in the treatment of TMD might be the following: presence of pain, joint sounds, alterations of jaw movements and muscle tenderness. [14]

2. What are the disadvantages or side effects of LLLT?

None of the articles studied up to now mentions any side effects of the LLLT. The intensity of the laser used in maxillofacial areas does not harm the tissues, but can cause biochemical effects on the cells [15]. The team lead by Da Chunha indicated that a lowlevel laser could penetrate tendons or the joint capsule, decrease the prostaglandin (PGE2) level in vivo, and cause inflammation [16]. Venancio and his fellow researchers came to the conclusion that LLLT could increase the discharge of urine glucocorticoid, a synthetic inhibitor of endorphin, to generate an analgesic effect [17].

3. What is the most appropriate or accurate working protocol for the LLLT?
When it comes to the question of the correct laser parameters to be used in TMD therapy, an interesting selection of the literature was made by Maia ML et al. They established that in the laser application protocol the energy density ranged from 0.9 to $105 \mathrm{~J} / \mathrm{cmÇ}$, while the power density, from 9.8 to $500 \mathrm{~mW}$. The number of sessions varied from 1 to 20 and the application frequency ranged from daily for 10 days to 1 time per week for 4 weeks [18].

4. What are the results of the LLLT use?

A careful selection of the literature was made by Chen et al, its value being assessed by the modified Jadad scale. They evaluated only articles that presented LLLT and placebo groups with a higher degree of inclusion criteria and well-established parameters. In terms of pain relief, using the visual analogue scale, 10 out of the 14 studies taken into consideration proved no significant difference between the two groups. The function of the TMJ was also taken into consideration in terms of maximum active vertical opening (MAVO), maximum passive vertical opening (MPVO), protrusion excursion (PE), right and left lateral excursion (RE and LE), measured in millimeters. In terms of function, LLLT proved to be effective in two of five studies, except for lateral excursion movements [19].

A review conducted by Xu GZ carefully selected 31 articles that proved a positive effect on pain in two thirds of the discussed cases. On the whole, in all the cases taken into consideration, the use of LLLT led to various degrees of improvement of pain and oral function in TMD when compared to the placebo group. In nine of the 31 studies, the authors stated that no side effects of the LLLT therapy were noticed [9]. The other few more articles [20] also taken into consideration are listed in the following table 1.

\section{Conclusion}

The current literature offers the clinician a wide range of results concerning treatment options of the TMD. LLLT is considered to be safe and easy to use. The heterogeneous laser parameters found in the scientific data bases do not allow the elaboration of a certain practical guideline. Although the results of using LLLT to reduce pain in cases of TMD are encouraging, a consensus is yet to be reached.

\section{Conflicts of Interest}

The authors declare that they have no potential conflicts of interest with respect to the research, authorship, and/or publication of this article. 
Table 1: General information about the studies included in this article

\begin{tabular}{|c|c|c|c|c|}
\hline Author / year & $\begin{array}{l}\text { Evaluated } \\
\text { Studies }\end{array}$ & LLLT effect on pain & $\begin{array}{l}\text { LLLT effect on } \\
\text { function }\end{array}$ & $\begin{array}{l}\text { Inconclusive results } \\
\text { or no effect of the } \\
\text { LLLT }\end{array}$ \\
\hline Chen et al, 2014 & 14 & $\begin{array}{l}10 \text { studies reported } \\
\text { no significant } \\
\text { difference in pain } \\
\text { relief between the } \\
\text { two groups }\end{array}$ & $\begin{array}{l}5 \text { studies reported an } \\
\text { improvement of the } \\
\text { MAVO, } 2 \text { studies of } \\
\text { the MPVO and of the } \\
\text { PE }\end{array}$ & \\
\hline Xu GZ et al, 2018 & 31 & $\begin{array}{l}17 \text { studies reported } \\
\text { positive effect in } \\
\text { reducing pain }\end{array}$ & $\begin{array}{l}3 \text { studies reported } \\
\text { positive effect on } \\
\text { masticatory } \\
\text { efficiency }\end{array}$ & 10 studies \\
\hline Maia ML et al, 2012 & 14 & $\begin{array}{l}13 \text { reported pain } \\
\text { relief }\end{array}$ & not evaluated & $\begin{array}{l}4 \text { studies reported } \\
\text { pain relief in both } \\
\text { experimental and } \\
\text { placebo group }\end{array}$ \\
\hline Petrucci A et al, 2011 & 6 & $\begin{array}{l}\text { not significantly } \\
\text { different from the } \\
\text { placebo group }\end{array}$ & $\begin{array}{l}\text { positive effects on } \\
\text { maximum vertical } \\
\text { opening }\end{array}$ & \\
\hline
\end{tabular}

\section{Bibliography}

1. Okeson JP: Bell's Orofacial Pain 7th ed. Quintessence Publishing Inc., Chicago, II, 2014.

2. De Leeuw R, Klasser G. Orofacial Pain: Guidelines for Assessement, Diagnosis and Management. 5th ed. Chicago: Quintessence Publishing Co., Inc. 2013.

3. Schiffman E, Ohrbach R, Truelove E, et al; International RDC/TMD Consortium Network, International association for Dental Research; Orofacial Pain Special Interest Group, International Association for the Study of Pain. Diagnostic criteria for temporomandibular disorders (DC/TMD) for clinical and research applications: recommendations of the International RDC/TMD Consortium Network and Orofacial Pain Special Interest Group. J Oral Facial Pain Headache 2014;28:6-27.

4. Henry CH, Hughes CV, Gerard HC, Hudson AP, Wolford LM. Reactive arthritis: preliminary microbiologic analysis of the human temporomandibular joint. J Oral Maxillofac Surg 2000;58:1137-1142.
5. Ren YF, Isberg A, Westesson P-L. Steepness of the articular eminence in the temporomandibular joint. Oral Surg Oral Med Oral Pathol Oral Radiol Endod 1995;80:258-266

6. Kurita H, Ohtsuka A, Kobayashi H, Kurashina K. Flattening of the articular eminence correlates with progessive internal derangement of the temporomandibular joint. Dentomaxillofac Radiol 2000;29:277-279.

7. Nekora-Azak A. Temporomandibular disorders in relation to female reproductive hormones: a literature review. J Prosthet Dent 2004;91:491493.

8. Hirsch C, Jhon MT, Stang A. Association between generalized joint hypermobility and signs and diagnoses of temporomandibular disorders. Eur J Oral Sci 2008;116:525-530.

9. Xu GZ, Jia J, Jin L, Li JH, Wang ZY, Cao DY. Low-Level Laser Temporomandibular Disorders: A Systematic Review with Meta-Analysis. Pain Res Manag. 2018 May 10;2018 
10. Shamseer L, Moher D, Clarke M, Ghersi D, Liberati A, Petticrew M, et al. Preferred reporting items for systematic review and meta-analysis protocols (PRISMA-P) 2015: elaboration and explanation. BMJ. 2015;349:g7647.

11. Moher D, Liberati A, Tetzlaff J, Altman DG, Group P. Preferred reporting items for systematic reviews and meta-analyses: the PRISMA statement. PLoS Medicine. 2009;6(7):e1000097.

12. Page MJ, Moher D. Evaluations of the uptake and impact of the Preferred Reporting Items for Systematic reviews and Meta-Analyses (PRISMA) Statement and extensions: a scoping review. Systematic Reviews. 2017;6(1):263.

13. Karu $T$ (1998) The science of low power laser therapy. Gordon and Beach Science, Amsterdam.

14. Sayed N, Murugavel C, Gnanam A. Management of Temporomandibular Disorders with Low Level Laser Therapy. J. Maxillofac. Oral Surg.2014;13(4):444-450.

15. Chang WD et al. A Meta-analysis of Clinical Effects of Low-level Laser Therapy on Temporomandibular Joint Pain. J. Phys. Ther. Sci.2014;26:1297-1300.

16. da Cunha LA, Firoozmand LM, da Silva AP, et al.: Efficacy of low-level laser therapy in the treatment of temporomandibular disorder. Int Dent J. 2008, 58: 213-217.

17. Venancio RA, Camparis CM, Lizarelli RF: Low intensity laser therapy in the treatment of temporomandibular disorders: a double-blind study. J Oral Rehabil, 2005, 32: 800-807.

18. Maia ML, Bonjardim LR, Quintans Jde S, Ribeiro MA, Maia LG, Conti PC. Effect of low-level laser therapy on pain levels in patients with temporomandibular disorders: a systematic review. J Appl Oral Sci. 2012 NovDec;20(6):594-602.

19. Chen J, Huang Z, Ge M, Gao M. Efficacy of lowlevel laser therapy in the treatment of TMDs: a meta-analysis of 14 randomised controlled trials. J Oral Rehabil. 2015 Apr;42(4):291-9.

20. Petrucci A, Sgolastra F, Gatto R, Mattei A, Monaco A. Effectiveness of low-level laser therapy in temporomandibular disorders: a systematic review and meta-analysis. J Orofac Pain. 2011 Fall;25(4):298-307.

21. Emshoff R, Bösch R, Pümpel E, Schöning $H$, Strobl H. Low-level laser therapy for treatment of temporomandibular joint pain: a double-blind and placebo-controlled trial. Oral Surg Oral Med Oral Pathol Oral Radiol Endod. 2008 Apr;105(4):4526.

22. Gil-Martínez A, Paris-Alemany A, López-deUralde-Villanueva I, La Touche R. Management of pain in patients with temporomandibular disorder (TMD): challenges and solutions. J Pain Res. 2018 Mar 16;11:571-587.

23. Salmos-Brito JA, de Menezes RF, Teixeira CE, Gonzaga RK, Rodrigues BH, Braz R, BessaNogueira RV, Gerbi ME. Evaluation of low-level laser therapy in patients with acute and chronic temporomandibular disorders. Lasers Med Sci. 2013 Jan;28(1):57-64.

24. Melis M, Di Giosia M and Zawawi K. Low Level Laser Therapy for the Treatment of Temporomandibular Disorders: A Systematic Review of the Literature. The Journal of Craniomandibular \& Sleep Practice . 2012:30(4), 304-312. 